\title{
The Missing Link in Language Development of Deaf and Hard of Hearing Children: Pragmatic Language Development
}

\author{
Dianne Goberis, M.A., ${ }^{1}$ Dinah Beams, M.A., ${ }^{2}$ Molly Dalpes, Au.D., 4 \\ Amanda Abrisch, Au.D., ${ }^{3}$ Rosalinda Baca, Ph.D., ${ }^{5}$ and \\ Christine Yoshinaga-Itano, Ph.D. ${ }^{5}$
}

\section{ABSTRACT}

This article will provide information about the Pragmatics Checklist, which consists of 45 items and is scored as: (1) not present, (2) present but preverbal, (3) present with one to three words, and (4) present with complex language. Information for both children who are deaf or hard of hearing and those with normal hearing are presented. Children who are deaf or hard of hearing are significantly older when demonstrating skill with complex language than their normal hearing peers. In general, even at the age of 7 years, there are several items that are not mastered by $75 \%$ of the deaf or hard of hearing children. Additionally, the article will provide some suggestions of strategies that can be considered as a means to facilitate the development of these pragmatic language skills for children who are deaf or hard of hearing.

KEYWORDS: Deaf, hard of hearing, pragmatic language development

\begin{abstract}
Learning Outcomes: As a result of this activity, the reader will be able to (1) identify the pragmatic language skills that children who are deaf or hard of hearing have the most difficulty mastering by 7 years of age;

(2) identify the pragmatic language skills that are the latest developed with complex language for children with normal hearing; (3) differentiate the rate of pragmatic language development by age and degree of hearing loss; (4) compare and contrast the pragmatic language skills of children with normal hearing and children who are deaf or hard of hearing by age; and (5) develop teaching strategies for preschool-aged children who are deaf or hard of hearing to develop specific pragmatic language skills that are typically developed significantly later than children with normal hearing.
\end{abstract}

${ }^{1}$ Mountain View Elementary School; ${ }^{2}$ Colorado Home Intervention Program, Colorado Springs, Colorado; ${ }^{3} \mathrm{Lu}-$ cile Packard Children's Hospital, Palo, Alto, California; ${ }^{4}$ Marion Downs Hearing Center; ${ }^{5}$ Department of Speech, Language, and Hearing Sciences, University of Colorado, Boulder, Colorado.

Address for correspondence and reprint requests: Christine Yoshinaga-Itano, Ph.D., Department of Speech, Language, and Hearing Sciences, University of Colorado, CB 409, Boulder, CO 80309-0409 (e-mail: Christie.yoshi@colorado.edu).
Maximizing Intervention for Children Who Are Deaf and Hard of Hearing; Guest Editors, Cheryl DeConde Johnson, Ed.D. and Christine Yoshinaga-Itano, Ph.D.

Semin Speech Lang 2012;33:297-309. Copyright (C) 2012 by Thieme Medical Publishers, Inc., 333 Seventh Avenue, New York, NY 10001, USA. Tel: +1(212) 5844662.

DOI: http://dx.doi.org/10.1055/s-0032-1326916.

ISSN 0734-0478. 
Early identified children who are deaf or hard of hearing $(\mathrm{DHH})$ who are enrolled in a timely manner into appropriate early intervention programs with providers who have specialized skills and knowledge in developmentally appropriate, parent-centered intervention with specialization in deafness and hearing loss have developed language skills in some areas that are similar to their typically hearing peers. Yoshinaga-Itano et $\mathrm{al}^{1}$ found that children who are DHH with normal cognition who are identified and receive intervention prior to 6-months of age, develop language skills at 7 years of age within the normal range of normally hearing peers on tests of expressive and receptive language- the Expressive One-Word Picture Vocabulary Test and the Test for Auditory Comprehension of Language. Unlike the generation prior to universal newborn hearing screening with appropriate early intervention services, this population is able to maintain a rate of development established in the early years of life. As a result, children who previously gained language at a rate of 45 to $65 \%$ of the rate of normally hearing children, now have the capability of gaining language at 80 to $100 \%$ the rate of children with normal hearing. The focus on the development of language skills for children who are DHH has concentrated on vocabulary development and size of the lexicon as well as receptive and expressive syntax. Although these are essential parts of language development that facilitate communication, one important aspect of language development in this population has been largely overlooked. Having the tools of vocabulary, expressive, and receptive language are indeed essential for communication. However, it is also important that children are able to use these tools effectively in social interactions with peers. This important component of language development that addresses an individual's ability to use language skills appropriately in social context is called pragmatics. It has been an aspect of language development at the most abstract level.

Several studies have assessed the pragmatic development of children with disorders that affect a child's ability to communicate with peers, such as autism or specific language impairment (SLI). However, deafness and hearing loss are disorders that greatly impact communication, yet have not been widely studied in the realm of pragmatic development. Thus, it is essential that researchers understand the pragmatic skills of $\mathrm{DHH}$ children to determine whether there is a need for pragmatic skills intervention to support communication.

One study in particular, which looked at 11-year-old children with SLI, found a significant correlation between pragmatic language difficulties and poor social outcome as well as expressive language related to victimization. ${ }^{2}$ These researchers assessed a group of 242 11-year-old children using a variety of questionnaires, which were administered to the children as well as their teachers. Pragmatic difficulties were determined using the Children's Communication Checklist, which is a commonly used questionnaire to determine pragmatic language impairment separate from typical SLI. Victimization was based on scores from the My Life in School questionnaire, which is filled out by the child and can predict whether she or he is at risk for victimization. Using regression analysis, the most prominent correlation was found between responses to these two instruments.

Similar studies have been done to assess "social cognition" of children with SLI. Research conducted by Marion Farmer ${ }^{3}$ assessed social cognition of four different groups of 10 - and 11-year-old children: (1) children with SLI attending a special school, (2) children with SLI attending a mainstream school, (3) control group with chronological age-matched peers without SLI, and (4) control group with language age-matched peers without SLI. The results indicated that children with SLI in the special school showed significant deficits in social competence in comparison to the other three groups. These findings provide insight into the social language use of children with communication deficits, such as SLI, who are not integrated into a mainstream school. These results suggest that children who are at risk for communication difficulties, such as children with hearing loss, should receive intervention in the mainstream classroom to prevent lower social competence than children in specialized schools.

Additional studies have found that children between the ages of 7 and 9 years of age 
who score high on the Children's Communication Checklist, thus identifying pragmatic language impairment, are identified by teachers as having socioemotional difficulties. ${ }^{4}$ Thus, children with pragmatic difficulties are likely to be perceived as having deficits in social and emotional development. Children who are $\mathrm{DHH}$ may also have socioemotional deficits that are manifested in pragmatic difficulties due to reduced communication abilities impacted by difficulties in access to both spoken and visual language. The question still remains, however, of how DHH children who were identified early (prior to 6 months, with the majority by 3 months of age) develop pragmatically as compared with normally hearing peers.

Though research specifically done on pragmatic development of children who are $\mathrm{DHH}$ is not prevalent, several studies have looked at multiple aspects of language development of $\mathrm{DHH}$ children, including language use. The recurring theme found in this literature indicates that children who are $\mathrm{DHH}$ who communicate using oral language are found to use more directive (instrumental) and less informational (heuristic) language skills than expected for their chronological age when compared with normally hearing peers. ${ }^{5-7}$ Nicholas $^{6}$ for example, assessed the use of directing, instrumental, and heuristic language in children with profound hearing loss as compared with normally hearing children. Results from this study determined that 3-year-old children with hearing loss who have mature language skills (e.g., increasing vocabulary size and sentence length) display social interactions using appropriate informational language skills. This suggests that $\mathrm{DHH}$ children who develop age-appropriate language milestones are likely to develop age-appropriate informative pragmatic skills as well.

Furthermore, researchers have found that 3-year-old children who are DHH who communicate orally, are more likely to use more directive communication functions than informative functions as compared with their normally hearing age-matched peers. ${ }^{7}$ These findings suggest that the pragmatic development of DHH children is delayed when compared with the typical pragmatic development of normally hearing peers. However, these studies, conducted in the 1990s and early 2000s, included predominantly children who were not identified through universal newborn hearing screening programs.

Most et $\mathrm{al}^{8}$ conducted a study of 24 children with hearing loss, 13 children with hearing aids and 11 children with cochlear implants, between the ages of 6.3 and 9.4 years of age compared with 13 children with normal hearing. Pragmatic abilities were assessed with the pragmatic protocol of Prutting and Kirchner. ${ }^{9}$ Children with hearing aids and those with cochlear implants had similar pragmatic language abilities. Children with hearing loss had significantly less effective and less flexible pragmatic language abilities than their normally hearing peers.

Preliminary data from Yoshinaga-Itano ${ }^{10}$ described the pragmatic skills of $54 \mathrm{DHH}$ preschool age children (3- and 4-year-olds). Pragmatic skills were determined using the Pragmatics Checklist, ${ }^{11,12}$ which looks at seven categories: instrumental ("I want"), regulatory ("Do as I tell you"), interactional ("me and you"), personal ("Here I come"), heuristic ("Tell me why"), imaginative ("Let's pretend"), and informative ("I've got something to tell you"). These categories have previously been used to describe pragmatic skills of typically hearing preschool-age children. ${ }^{12}$ Of the mentioned categories, skills were rated as either "not present" or "regularly present." In this group of children with hearing loss, 3-year-old pragmatic skills that were most often ( $\geq 50 \%$ of responses) "not present" included: giving directions, revision of unclear messages, respect for alternative points of view, explanation of feelings, telling an adult what is not understood in accusation, offering opinions on an issue and supplying supportive statements for opinion, supplying basic identification and biographic data, asking questions for clarification, creating stories with beginning-logical eventsconclusion, using precise noun/pronoun referents, engaging in evaluation of an object in contrast to another, and evaluating the quality of an event. Skills rated most often $(\geq 50 \%$ of responses) as "not present" in the 4-year-old group included: revision of unclear message and evaluating the quality of an event. These data are difficult to interpret because there is no data on normal hearing age-matched peers using this Pragmatics Checklist instrument. Thus, it was essential that the Pragmatics Checklist be 
distributed to typically hearing preschool-aged children so comparisons can be made between pragmatic development of $\mathrm{DHH}$ preschoolers to typically hearing preschoolers.

In the 1999 analysis, the Pragmatic Checklist outcomes for children who are $\mathrm{DHH}$ had significant and strong relationships to the Minnesota Comprehension-Conceptual (a measure of receptive language), the Minnesota Expressive Language, and the MacArthur Expressive $\mathrm{Vo}^{-}$ cabulary subtests at both the 3- and 4-year-old levels. At the 3-year age level, the Pragmatic Checklist subtests were not significantly related to the MacArthur Expressive Vocabulary subtest. The pragmatic language skills were significantly related to the Minnesota Child Development Inventory (MCDI) subtests and ranged from $r=0.45$ to 0.84 . At the 4-year age level, the correlations ranged from $r=0.69$ to 0.85 for the Minnesota subtests and $r=0.55$ to 0.84 for the MacArthur subtest. The seven pragmatic categories at the 4-year age level were highly related to the Personal-Social subtest of the Minnesota, $r=0.49$ to 0.81 , but at the 3-year level only three of the seven categories had a significant relationship to the Personal-Social subtest: instrumental $(r=0.45)$, heuristic $(r=0.59)$, imaginative $(r=0.58)$. This finding may indicate that the interaction between social interaction and pragmatic language skills becomes stronger as the child ages, as does the relationship between vocabulary and pragmatic language skills.

If a reciprocal relationship between pragmatic language skills, vocabulary growth, and syntax development exists, improvement in any aspect should be beneficial to the other aspects of language. Although the typically developing child with normal hearing learns pragmatic language skills through incidental learning, the child with a significant hearing loss often requires specific instruction to understand the importance of these skills and to learn the content knowledge.

\section{METHODOLOGY}

\section{Participants with Normal Hearing}

The subject population included children ages 2 - to 7-years-old with normal hearing. This project focused on collecting data for $\sim 30$ to 50 children in each age group. Seven demographic questions existed on this questionnaire to ensure that the control group met inclusion/ exclusion criteria and to mitigate confounding variables that may affect interpretation of the obtained results. The seven demographic questions asked for the following: child's birth date and gender, parental level of education, child's diagnoses, child's educational setting (daycare or preschool), child's ethnicity, and languages spoken in the home. To match the control group (normal hearing children) with the experimental group (DHH children), the demographic questions asked on the large-scale study were also asked on an online questionnaire. Child's age, gender, ethnicity, language, and educational setting are important for matching the control and experimental groups as closely as possible. The mother's level of education was necessary because research shows that maternal level of education is a predictive factor in $\mathrm{DHH}$ language outcomes. ${ }^{13} \mathrm{~A}$ diagnosis of additional disabilities including autism, speech/language disorder, or cognitive/developmental delay was also requested because these diagnoses are known to impact communication skills.

Inclusion criteria were: a signed consent form, questionnaire completed in its entirety, child within the age criteria of 2- to 7-years-old and whose cognitive age is equivalent to his or her chronological age. Exclusion criteria were: no consent form or missing information on the questionnaire, children who do not meet the age criteria, children diagnosed with developmental delays or with a cognitive age below their chronological age, children with diagnosis of autism or speech/language disorder, or children diagnosed with hearing loss. Children with developmental or cognitive delays were not to be included in this study because research emphasizes that DHH children with age-appropriate cognition who receive intervention by 6 months of age are able to develop ageappropriate language skills similar to typically hearing children. ${ }^{14}$ Children with autism, speech/language disorder, or other additional disabilities impacting language development were excluded from this study. The main goal for this control group of normally hearing children is that they have typically developing communication and language skills. 


\section{APPENDIX}

Child's Name:

Person Completing Form:

Relationship to Child:

Date Completed:

\section{Instrument for Participants}

The Pragmatic Checklist with 45 items was adapted from Simon ${ }^{12}$ (see Appendix). There were 96 total items on the online survey, one question asking for consent to participate, seven demographic questions, 45 pragmatic checklist items, and 43 situation comprehension survey items. The Pragmatics Checklist is a questionnaire for parents to describe their child's pragmatic skills. It includes six categories: states needs, gives commands, personal, interactional, wants explanations, and shares knowledge and imaginations. Each category consists of several pragmatic skills for parents to rate their child's ability as not present, uses no words (preverbal), uses one to three words, and uses more complex language. For example, under the objective of shares knowledge and imaginations, parents rate the child's ability to role-play with different characters, role-play with props, retell a story that has been told to them, etc. A copy of the checklist is located in the Appendix.

The situation comprehension questions ask parents to answer yes or no to 43 different nonverbal behaviors. Examples of nonverbal behaviors on this checklist include: looks both ways before crossing the street, recognizes mother, looks for an object after it disappears from sight. These questions are taken from the Situation Comprehension subtest of the 1972 MCDI, which is a parent report questionnaire developed by Harold Ireton. There is a newer version of the MCDI, which was published in 1994. The 1972 version of the MCDI is no longer available and no longer has an active copyright. It is important to include these questions in this study of normal hearing children because they were used in the large scale study of DHH children to determine nonverbal cognitive function, which may account for variance in the pragmatics checklist.

This checklist has been distributed through paper copies; however, distributing the Prag- matics Checklist using an online questionnaire dramatically increased the number of responses. The survey included the exact 45 questions on the paper version with seven additional demographic questions and 43 questions regarding situation comprehension nonverbal skills. One significant difference between the online version and the paper version was the fact that parents filling out the online survey must sign the parent consent form by checking the consent box rather than giving a physical signature. The estimated time commitment to complete the checklist was 10 minutes. All parents of children with normal hearing who had access to the Hands \& Voices Web site (http://www. handsandvoices.org/) were invited to participate in this research study. Additionally, participants were solicited through email via the Hands \& Voices email contact list. There were over 1200 contacts on the Colorado state Hands $\&$ Voices email list and the Web site is available to $30+$ state chapters as well as international chapters. It is unknown how many of these families who are a part of the Hands \& Voices organization nationally and internationally have children with normal hearing who fall into the target age range for this project. The parents of children with normal hearing had knowledge about language development because they were parents who also had a child who was $\mathrm{DHH}$ and if the parents resided in Colorado, they had also filled out this checklist on their DHH child.

\section{RESULTS}

\section{Characteristics of the Participants}

There were 109 children in the group of children with normal hearing $(\mathrm{NH})$ ranging from 2 to 7 years of age. All of the children had $\mathrm{NH}$ by parent report and normal cognition based on the Situation Comprehension subscale 
PRAGMATICS CHECKLIST: Check the Column That Best Fits the Child's Language Skills

\begin{tabular}{|c|c|c|c|c|}
\hline Pragmatic Objective & $\begin{array}{l}\text { Not } \\
\text { Present }\end{array}$ & $\begin{array}{l}\text { Uses } \\
\text { No Words } \\
\text { Preverbal }\end{array}$ & $\begin{array}{l}\text { Uses One to } \\
\text { Three Words }\end{array}$ & $\begin{array}{l}\text { More Complex } \\
\text { Language }\end{array}$ \\
\hline
\end{tabular}

States Needs

(I want ...)

Makes polite requests

Makes choices

Gives description of an object wanted

Expresses a specific personal need

Requests help

Gives Commands

(Do as I tell you ...)

Gives directions to play a game

Gives directions to make something

Changes the style of commands or requests

depending on who the child is speaking

to and what the child wants

Personal

(Expresses Feelings ...)

Identifies feelings (I'm happy)

Explains feelings (I'm happy because it's

my birthday)

Provides excuses or reasons

Offers an opinion with support

Complains

Blames others

Provides pertinent information on request

(two or three of the following: name,

address, phone number, birth date)

Interactional

(Me and You ...)

Interacts with others in a polite manner

Uses appropriate social rules such as

greetings, farewells, thank-yous,

attention-getting tactics

Attends to the speaker

Revises/repairs an incomplete message Initiates a topic of conversation (doesn't just start talking in the middle of a topic) Maintains a conversation (able to keep it going)

Ends a conversation (doesn't just walk away)

Interjects appropriately into an already established conversation with others Makes apologies or gives explanations of behavior

Requests clarification 
(Continued)

\begin{tabular}{|c|c|c|c|c|}
\hline Pragmatic Objective & $\begin{array}{l}\text { Not } \\
\text { Present }\end{array}$ & $\begin{array}{l}\text { Uses } \\
\text { No Words } \\
\text { Preverbal }\end{array}$ & $\begin{array}{l}\text { Uses One to } \\
\text { Three Words }\end{array}$ & $\begin{array}{l}\text { More Complex } \\
\text { Language }\end{array}$ \\
\hline
\end{tabular}

States a problem

Criticizes others

Disagrees with others

Compliments others

Makes promises

Wants Explanations

(Tell me Why ...)

Asks questions to get more information

Asks questions to systematically gather

information (20 Questions)

Asks questions because of curiosity

Asks questions to problem solve

(What should I do ... ?, How do I know ...?)

Asks questions to make predictions

(What will happen if ...?)

Shares Knowledge and Imaginations

(I've got something to tell you ...)

Role-plays as/with different characters

Role-plays with props (banana as a phone)

Provides a description of a situation that

describes the main events

Correctly retells a story which has been

told to them

Relates the content of a four- to six-frame picture

story using correct events for each frame

Creates an original story with a beginning, several

logical events, and an end

Explains the relationship between two objects,

actions, or situations

Compares and contrasts qualities of two objects,

actions, or situations

Tells a lie

Expresses humor/sarcasm

Source: Goberis D. (Adapted from work done by Simon. ${ }^{11}$ )

of the MCDI. Data for the children with $\mathrm{NH}$ was analyzed for groups ranging between the ages of 18 to 29 months $(n=14), 30$ to 41 months $(n=19), 42$ to 53 months $(n=21), 54$ to 65 months $(n=23), 66$ to 77 months $(n=17), 78$ to 89 months $(n=11)$ and $90+$ months $(n=4)$.

There were 126 participants who were $\mathrm{DHH}$ between the ages of 3 and 7 years. All children had normal cognitive development and their hearing losses covered all levels. Pragmatic language checklist data were available for (1) 93 children between 24 to 35 months of age (most evaluations were completed at $\sim 33$ months of age), (2) 50 children aged 36 to 47 months, (3) 102 children aged 48 to 59 months, (4) 89 children aged 60 to 71 months, (5) 82 children aged 72 to 83 months, and (6) 67 children aged 84 to 96 months.

\section{GENDER}

Forty-three percent of the children with $\mathrm{NH}$ were male, $56 \%$ were female, and $1.8 \%$ were unspecified. Fifty-one percent of the children 
who were $\mathrm{DHH}$ were male and $49 \%$ were female.

\section{AGE AT TESTING}

There was a higher percentage of 2-year-oldchildren who had NH (12.8\%) than those who were $\mathrm{DHH}(0.3 \%)$ and a higher percentage of 3 -year-old children with $\mathrm{NH}(17.4 \%)$ than children who were DHH (8.9\%). The percentage of 4-year-old children with $\mathrm{NH}(19.3 \%)$ and those who were $\mathrm{DHH}(20.6 \%)$ and the percentage of 5-year-old children with NH (21.2\%) and children who were DHH (23.88\%) were similar. There was a higher proportion of 6-year-old children who were DHH (24.5\%) than those that had NH (15.6\%) and a higher proportion of 7-year-old children (21.8\%) who were $\mathrm{DHH}$ than $\mathrm{NH}(10.1 \%)$. Of the children at 8-yearsold, 3.7\% had NH. There were no 8-year-old children who were $\mathrm{DHH}$.

\section{MATERNAL LEVEL OF EDUCATION}

There were differences in the maternal level of education of the children with normal hearing and the children who were $\mathrm{DHH}$. Of the mothers of children who were $\mathrm{DHH}, 6.4 \%$ had below a high school education as compared with none of the children with $\mathrm{NH}$. Of the mothers of children who were DHH, 36.5\% had a high school diploma compared with $13.8 \%$ of the children with normal hearing. Of mothers of the children with $\mathrm{NH}, 5.5 \%$ had an associate's degree as compared to $10.3 \%$ of the children who were $\mathrm{DHH}$. Of the mothers of children who were NH, 35.8\% had a bachelor's degree as compared with $32.5 \%$ of mothers of children who were DHH. Of mothers who had children with $\mathrm{NH}, 30.5 \%$ had a master's degree as compared with $11.9 \%$ of the mothers who had children who were DHH. Of the mothers who had children with $\mathrm{NH}, 11 \%$ had a doctorate as compared with $1.6 \%$ of the mothers of children who were $\mathrm{DHH}$. Less than $1 \%(0.9 \%)$ in the $\mathrm{NH}$ group compared with $0.8 \%$ in the DHH group had unspecified maternal level of education.

\section{ETHNICITY OF THE GROUP}

Sixty percent of the NH group and $68.3 \%$ of the $\mathrm{DHH}$ children were Caucasian, $1.8 \%$ of $\mathrm{NH}$ and $19 \%$ of $\mathrm{DHH}$ children had a Hispanic/
Latino background, $1.8 \%$ of $\mathrm{NH}$ and $5.6 \%$ of the $\mathrm{DHH}$ were Asian American, $10.1 \%$ of the $\mathrm{NH}$ and $7.1 \%$ of the $\mathrm{DHH}$ children indicated "other." Twenty-six percent of the NH group did not specify and $0 \%$ of the DHH group did not specify.

\section{LANGUAGES USED IN THE HOME}

Of the NH group, 93.6\% used English only as compared with $31.7 \%$ of the DHH group. Of the $\mathrm{NH}, 6.4 \%$ indicated homes with bilingual spoken languages as compared with $4.8 \%$ of the DHH group; $57.9 \%$ of the DHH group indicated that they used English and sign language and $5.6 \%$ of the $\mathrm{DHH}$ group indicated that they were bilingual spoken language and sign language homes.

\section{DEGREE OF HEARING LOSS}

In the $\mathrm{DHH}$ group there were $19.8 \%$ with mild hearing loss, $24.2 \%$ with moderate to moderate-severe hearing loss, $32.9 \%$ with severe hearing loss, and $23.1 \%$ with profound hearing loss.

\section{Test Results}

Mastery of the items was defined as $75 \%$ of the children using complex language for each item. Children with normal hearing mastered $44 \%$ (20 of 45) of the items using complex language by 3 years of age. By 4 years of age, they mastered 95.5\% (43 of 45) of the items. By 5 years of age they mastered $98 \%$ of the items. By 6 years, they mastered 100\% of the items with complex language. The final two items mastered were: (1) provides information on request (name, date of birth, address [two or three items]) and (2) makes promises. The results of children who are $\mathrm{DHH}$ by age and the results of children with normal hearing by age and by item can be found on the Web site www.mariondowns.com/research/pediatrics.

In contrast, children who are $\mathrm{DHH}$ mastered only $6.6 \%$ (3 of 45 ) of the items with complex language by 6 years of age. They mastered 69\% (31 of 45) of the items with complex language by 7 years of age (see Fig. 1). The three items accomplished by 6 years were: (1) makes polite requests-uses words: please, thank you, (2) expresses needs, and (3) role-plays with props. 


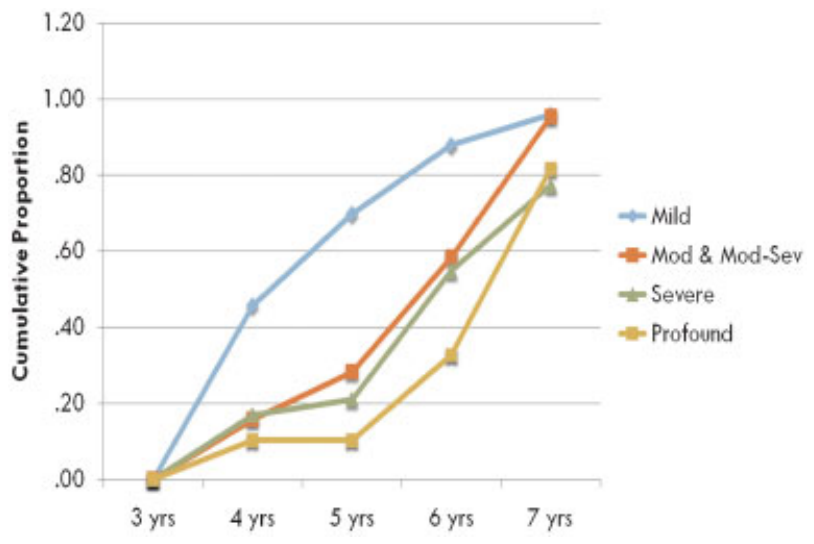

Figure 1 Pragmatics Checklist items mastered by age.

Items not mastered with complex language by children who are $\mathrm{DHH}$ by 7 years of age were: (1) provides information on request, (2) repairs incomplete sentences, (3) ends conversations, (4) interjects, (5) apologies, (6) request clarification, (7) makes promises, (8) asks questions to problem solve, (9) asks questions to make predictions, (10) retells a story, (11) tells four- to six-frame picture story in right order, (12) creates original story, (13) explains relationships between objects-action-situations, and (14) compares and contrasts.

\section{Differences by Degree of Hearing Loss}

Figure 1 depicts the proportion of items mastered by age by degree of hearing loss. Children with mild hearing had the fastest development but were delayed compared with children with normal hearing. From 3 to 6 years of age, children with moderate and moderate severe hearing loss had mastered significantly fewer pragmatic skills with complex language, but by 7 years of age, they were similar. Children with severe and profound hearing loss had a similar rate of mastery of pragmatic skills through age 7. By 7 years of age, they had mastered $\sim 80 \%$ of the items.

\section{Intervention Strategies}

Parents often wonder what language skills they can work on in the home. This questionnaire helps parents target specific language skills to model within the home providing natural opportunities for the child to practice them. If the child is in an integrated environment, the teacher questionnaire helps identify some of the strengths and weaknesses of the child's language abilities and the teacher may then optimize language learning in classroom situations where these strategies could be naturally practiced. Teachers frequently judge language skills based upon the speech intelligibility of the child. However, pragmatic language skills are often so subtle that the teacher does not identify specific areas of delay or difficulty. In addition to the analysis of situations in which language becomes difficult, it is also possible to determine whether the student has sufficient vocabulary and grammatical capabilities to communicate his or her needs and wants. If the student lacks specific content knowledge in vocabulary or syntax, these skills can be taught through individualized intervention.

\section{Giving Directions}

Most early intervention specialists and speechlanguage pathologists (SLPs) work on simple commands such as understanding: go get your shoes, put your shoes on, open the door, get in the car. However, teachers and SLPs sometimes overlook having the child give directions to others. There are some pragmatic language skills that are important for giving directions, such as to play a game or to make something. To teach these skills, the SLP/teacher needs to carefully analyze all of the cognitive linguistic steps that must be understood to provide directions to another about playing a game or 
making something. The child needs to understand what is in the mind of the other individual who must learn a game or learn how to make something (i.e., theory of mind). Can the child explain the steps well enough so that another individual can successfully make something: a picture, a snowman, a peanut butter and jelly sandwich, or an arts and crafts activity?

\section{Making Something}

Children also need to learn the sequence of information that they need to tell someone else about how to make something. Even when the child understands the sequence and is capable of making the desired food item, arts and crafts project, or object, the child may be unable to explain to another how to do it. Children do not always understand what basic information is important for another person to know. Remember to teach sequence. For a peanut butter and jelly sandwich, if the child says "peanut butter" and omits specific instructions in the sequence, the teacher/SLP can respond with absurdities such as, "Do I put it in my hand? Where's the bread?"

The teacher/SLP needs to identify each of the steps in the sequence. It is often helpful to have pictures that are associated with each step in the sequence. Using a chart with pictures that depict each step in the process, children will cross out each step as they either do it, indicating comprehension, or as they tell another to do it, demonstrating the pragmatic expressive language skill. Then the teacher/SLP puts the items back in the right sequence to review. The order may also be jumbled to demonstrate that the end result will not be correct.

The teacher could teach the child the correct sequence with picture cues and written language: (1) get a banana, chocolate, and nuts, (2) peel the banana before cutting, (3) cut the banana, (4) dip the banana into the chocolate, (5) roll the chocolate-covered banana in nuts, (6) freeze the banana. Teaching requires redundancy and repetition. Make sure to let the child make mistakes. If it isn't in order, can the task be completed? Children need to learn that making things typically requires a specific order or sequence of events to accomplish the goal.

\section{Learning How to Play a Game}

At very young age levels, the teacher/SLP may want to teach a child to give directions about how to play a simple game, such as Duck Duck Goose. First, the child must consider the number of steps. Children must sit in a circle. There is a chosen child, the goose. How is the child chosen? Does the teacher pick the child, or does the child who suggests the game pick the chosen child? The chosen child walks around the outside of the circle. The child taps each child and says "duck" as he or she taps. The child must choose a child to be the goose. When a child is chosen as the goose, this child must get up quickly and run around the circle. The child who has chosen the child to be the goose also begins to run around the circle and whoever reaches the empty spot first and sits down, is no longer the goose. The chosen child who is the new goose must think about whom she or he will choose. The child must not show by eye gaze or pointing or any other hint who the new chosen child will be. If the goose does indicate who she or he will chose too early, then she or he will beat the chosen child to the open spot and the chosen child becomes the new the goose. The child must keep a secret. This is an opportunity to teach what a secret is.

The teacher/SLP may start out with a chart. The children take turns explaining how to play the game. The teacher/SLP may scaffold the activity by asking "What's first? What's second? What's third?" If the child simply says, "tap, tap, tap," the teacher/SLP must indicate that there is some missing information. "What's missing? Hmm," the teacher can then give some indication of the thinking process that should be used. It is important for the teacher/parent to teach the child the thought process: "Who should I pick? It's a secret. Don't tell anyone. Don't make eye contact, others will notice. Don't point at the child you pick. If the child knows that you have chosen him or her, he or she will be prepared to run around the circle and you may not get there first."

The SLP or teacher may introduce an absurdity. "Can I pick the table? Why not? If I walk around the circle, I need to tap a person. If I tap a chair, the chair cannot get up and run around the circle to try to sit down in the open space first." 
This is an excellent opportunity for activities at home, such as how to teach games like Concentration, Candy Land, or card games to a sibling or a friend. Other games that can be described besides board games or card games are games with a ball, simple games like Duck Duck Goose, or games with teams.

\section{Teaching Perspective Taking}

It is important for children to learn how to understand what is in the minds of others. Teach "why" questions. Teach children how it makes them feel. Ask questions such as, "Does it make you feel angry? Sad? Or disappointed? Why are you upset? Are your feelings hurt? Which is better, Grab it or ask politely? If I take it from you, how does it feel?"

\section{Teach about Choices and What the Consequences Are for Each Choice}

With children who have high language skills, it is important to teach verbal mediation skills and the language appropriate for these pragmatic skills. For children with lower language skills, the teacher/SLP may want to use pantomime and pictures.

\section{Playing 20 Questions}

Although children with $\mathrm{NH}$ learn how to play the game 20 questions without having to learn the steps, children who are DHH often need specific instructions. How do you select the question to be asked? Which type of question is better, "Is it a dog? Is it alive? Is it an animal?" When the question is answered, what should the child do with the answer? Does the child eliminate any possibilities? It is easiest to learn how to play the game if the options are limited? With pictures of the possible answers, after the question is answered, it is possible to eliminate some of the pictures. Can the child explain why these answers would be eliminated? The child should cross out the pictures of answers that cannot be the chosen one because of the answer given to the previous question. Then the child needs to look at the remaining pictures and formulate a question that will either provide the information about which one is the chosen answer or eliminate more of the potential answers. The SLP may need to teach the child what questions might yield the best ability to eliminate answers. These questions are frequently category questions, such as "Is it alive?" or "Is it an animal?" The child must learn how to keep information in his or her head to use for formulating the next question. The child must understand how to categorize things. Categorization often begins with visual obvious characteristics, such as the color, "Is it white?" Or the size, "Is it big?" Or, "Is it alive?" Or, "How do animals move? Do they fly? Swim? Walk?"

\section{Recognizing a Falsehood}

To survive in this society, it is important that children understand the difference between truth and a lie. Children need to learn when they are being "tricked." They need to understand what it means to be gullible, so that social victimization can be prevented. Role-play can consist of pretending to be a trickster, such as "coyote" in the southwest of America. Should I believe the trickster? Are there any clues provided about tricksters? What strategies can be used to determine whether something is true or something is a lie? How does the child know when to believe someone? A child cannot understand truth without understanding a lie.

\section{Persuasion}

Why is it important for children to learn how to be persuasive? What are some real life examples when the child may find it important to persuade someone? A child may want to know how to persuade his or her parents to allow them to do something or get something; permission to do a particular activity, go to a party, go to get ice cream, etc. A child may also want to persuade other children to let him or her play with them. What are some strategies that can be used? How can the child assess whether or not the strategy is successful?

\section{Telling a Story in Sequence}

Children who are DHH often need to learn how to relate stories of events so that someone else can understand the story. Notebooks that go back and forth between the SLP/teacher and 
the home can include information about what events may be of importance to the child that occurred at home or after school. The SLP/ teacher can then ask the child to tell them information about what happened. Then it is possible to determine whether the child is capable of telling a story or event in a logical order with sufficient information for others to understand. A parent will also know if something significant or important occurred that day-so that if the child begins to talk about an event, the parent will be knowledgeable enough to help support the child in learning how to relate information to another person. Because the teacher/SLP knows the event, she or he is also able to determine what information has been omitted or is incomplete. The teacher/ SLP will want to determine if there is understanding of cause and effect. Information about comparing and contrasting may also be important when relating the information. Storytelling should improve if both the teacher/SLP and parent(s) provide appropriate modeling with emphasis on the components omitted by the child.

\section{Defense in the Face of False Accusation}

Is the child able to use language that provides defense in the face of a false accusation? Does the child understand the situation sufficiently to identify what defense would prove his or her innocence? Statements (e.g., "He took the toy. I didn't take the toy. I didn't want the toy. I wasn't in the vicinity. I don't have the toy. I didn't want the toy.") that provide evidence that the accusation is false could include a variety of perspectives.

\section{Alternate Points of View}

The child does not have to have the same point of view as another (e.g., "I like this book or song"). The child does not have to like the book or song (e.g., "He hates this book"). Questions that could stimulate thinking about alternative points of view could assist the child in thinking about another's perspective: "Why did you like this book? What was your favorite part? What is another student's favorite part? Does everyone like the book?"

\section{Revision of Unclear Message}

First the child must be able to identify when the message was unclear to another person. If they can identify miscommunication, then they can supply options. The teacher/SLP should model for the child. If the child says, "boat," the SLP/ teacher could question, "Do I want the boat? Do I want to eat the boat? Do you want to get on the boat? Is it a blue boat?"

\section{Ability to Answer Questions}

A response needs to be appropriate, not just a response. Imitation is not a response to a question. The SLP/teacher needs to model both correct and incorrect, or model an absurd response.

\section{Maintaining a Topic}

Sample questions might include "Tell me three things about what you did last night. What kind of things did you see? Hear? Can you picture that in your head? Can you picture what would happen in the restaurant? Can you picture what would happen in a store?"

\section{Theory of Mind}

Children often need to be explicitly taught how to think about predicting what is in the mind of another person. Children who are $\mathrm{DHH}$ often think that what they know, others also know. They need to be taught that a person knows what they have experienced and if they have not had access to specific information, they will make mistakes.

\section{SUMMARY}

The pragmatics of language development are the most abstract and complex language skills. Even when the child has age-appropriate vocabulary and syntax skills, she or he may not yet have learned how to use these skills in a socially appropriate manner for specific social purposes. Young children with NH acquire these skills rapidly between 3 and 4 years of age and are able to use these pragmatic language skills using complex language. Children who are $\mathrm{DHH}$ acquire these skills much more slowly even with targeted intervention strategies. Without mastery of these skills, children will encounter significant challenges with literacy, written 
communication, and abstract conversational communication.

\section{ACKNOWLEDGMENTS}

Data collection for children with $\mathrm{NH}$ and typical development and data analysis was made possible through a grant from Centers for Disease Control, Association of University Centers on Disability, CDC-AUCD 433, 470. Data collection was supported by the Centers for Disease Control and Prevention (grant/ cooperative agreement number UR3/ CCU824219), National Institutes of Health (contract number N01-DC-4-2141), Maternal and Child Health, the Colorado Department of Education (contract number H325D030031A, $\mathrm{H} 32 \mathrm{C} 030074)$, the University of Colorado at Boulder, the Colorado Home Intervention Program, and the Colorado Department of Public Health and Environment. We wish to acknowledge the contributions of the following individuals to this project: student coders, CHIP facilitators and the participating families.

\section{REFERENCES}

1. Yoshinaga-Itano C, Baca RL, Sedey AL. Describing the trajectory of language development in the presence of severe-to-profound hearing loss: a closer look at children with cochlear implants versus hearing aids. Otol Neurotol 2010;31: 1268-1274

2. Conti-Ramsden G, Botting N. Social difficulties and victimization in children with SLI at 11 years of age. J Speech Lang Hear Res 2004;47:145-161

3. Farmer M. Language and social cognition in children with specific language impairment. J Child Psychol Psychiatry 2000;41:627-636
4. Ketelaars MP, Cuperus JM, van Daal J, Jansonius $\mathrm{K}$, Verhoeven L. Screening for pragmatic language impairment: the potential of the children's communication checklist. Res Dev Disabil 2009;30: 952-960

5. Day PS. Deaf children's expression of communicative intentions. J Commun Disord 1986;19: 367-385

6. Nicholas JG. Age differences in the use of informative/heuristic communicative functions in young children with and without hearing loss who are learning spoken language. J Speech Lang Hear Res 2000;43:380-394

7. Nicholas JG, Geers AE. Communication of oral deaf and normally hearing children at 36 months of age. J Speech Lang Hear Res 1997;40: 1314-1327

8. Most T, Shina-August E, Meilijson S. Pragmatics abilities of children with hearing loss using cochlear implants or hearing aids compared to hearing children. J Deaf Stud Deaf Educ 2010;15: 423-437

9. Prutting CA, Kirchner DM. A clinical appraisal of the pragmatic aspects of language. J Speech Hear Disord 1987;52:105-119

10. Yoshinaga-Itano C. Assessment and intervention with preschool children who are deaf and hard-ofhearing. In: Alpiner J, McCarthy P, eds. Rehabilitative Audiology Children and Adults. Philadelphia, PA: Lippincott Williams \& Wilkins; 1999:140-177

11. Goberis D Pragmatics Checklist (adapted from work done by Simon CS, 1984):1984

12. Simon CS. Functional-pragmatic evaluation of communication skills in school-aged children. Lang Speech Hear Serv Sch 1984;15:83-97

13. Yoshinaga-Itano C, Gilkerson J. Paradigm shifting: automatic assessment of natural environments. Paper presented at: AG Bell 2010 Biennial Convention; June 25, 2010; Orlando, FL

14. Yoshinaga-Itano C, Sedey AL, Coulter DK, Mehl AL. Language of early- and later-identified children with hearing loss. Pediatrics 1998;102: 1161-1171 